September 2006

\title{
A Laboratory Investigation of Compliance Behavior under Tradable Emissions Rights: Implications for Targeted Enforcement
}

\author{
JAMES J. MURPHY ${ }^{\mathrm{a}, \mathrm{b}, \mathrm{c}, *}$ \\ JOHN K. STRANLUND ${ }^{a}$
}

a Department of Resource Economics, Stockbridge Hall, 80 Campus Center Way, University of Massachusetts-Amherst, Amherst, MA, 01003, USA

b Center for Public Policy and Administration, Thompson Hall, 200 Hicks Way, University of Massachusetts-Amherst, Amherst, MA, 01003, USA

c Department of Economics, Rasmuson Hall, 3211 Providence Drive, University of Alaska Anchorage, Anchorage, AK 99508

* $\quad$ Corresponding author. Fax + 14135455853

Email address: murphy@resecon.umass.edu

Running title: Enforcement of Permit Markets

Journal of Environmental Economics and Management. Accepted for publication. 


\title{
A Laboratory Investigation of Compliance Behavior under Tradable Emissions Rights: Implications for Targeted Enforcement
}

\begin{abstract}
This paper uses laboratory experiments to test theoretical predictions concerning compliance behavior in competitive emissions trading programs. We test the hypotheses that both the violations of competitive risk neutral firms and the marginal effectiveness of increased enforcement across firms are independent of differences in their benefits from emissions (abatement costs) and their initial permit allocations. This conclusion suggests that regulators have no conceptual justification for targeting their enforcement effort based on firm-level characteristics. Consistent with theory, we find that violations were independent of parametric differences in emissions benefits. However, subjects who were predicted to buy permits tended to have higher violation levels than those who were predicted to be sellers. Nevertheless, we find no evidence that the marginal effectiveness of enforcement depends on any firm-specific characteristic. We also examine the determinants of compliance behavior under fixed emissions standards. As expected, we find significant differences between compliance behavior under fixed standards and emissions trading programs.
\end{abstract}

Keywords: enforcement, compliance, emissions trading, permit markets, standards, commandand-control, laboratory experiments

JEL Codes: C91, L51, Q58 


\section{A Laboratory Investigation of Compliance Behavior under Tradable Emissions Rights: Implications for Targeted Enforcement}

\section{Introduction}

Although often overlooked, one of the most important design elements of any regulatory policy is how compliance with the policy will be enforced. Within the context of designing emissions trading programs, several authors have provided theoretical analyses of compliance incentives, the consequences of noncompliance, and strategies for enforcing emissions trading programs (e.g., Keeler [19], Malik [21], [22], [23], vanEgteren and Weber [34], Stranlund and Dhanda [32], Stranlund and Chávez [30]). Taken as a whole, this literature suggests that firms’ incentives toward noncompliance under market-based regulation, as well as the design of enforcement strategies to counteract these incentives, are quite different from compliance and enforcement of other policy instruments, particularly command-and-control regulations.

While there is a substantial body of economic theory about compliance and enforcement in emissions trading programs, there is limited empirical evidence regarding the determinants of compliance decisions in these programs. In this paper, we report the results of a series of experiments designed to examine some key factors that may affect compliance decisions. Our primary interest is whether differences in the individual characteristics of firms generate different compliance choices. This is an important issue because, on the face of it, one may suspect that firms with different production processes, abatement technologies, or initial allocations of permits may have different compliance incentives. If this is true, then regulators will be motivated to condition their enforcement efforts on firm-level characteristics.

Regulators might use information about firm-level determinants of compliance behavior in different ways depending on what their enforcement objectives are. If some firms tend toward higher violations than others, then a regulator that is primarily motivated to detect those with 
higher violations will direct greater enforcement effort toward these firms. On the other hand, suppose that a budget-constrained regulator seeks to distribute his enforcement effort to minimize aggregate violations. ${ }^{1}$ In this case, the regulator is not necessarily concerned about whether some firms have higher violations than others. His main concern is to direct enforcement effort to where it is most productive.

Conceptually, Stranlund and Dhanda [32] show that the individual compliance choices of risk neutral competitive firms in emissions trading programs are independent of differences in any firm-level characteristic. Consequently, regulators have no reason to condition their enforcement effort on firm-level characteristics. Their reasoning is straightforward. Since compliance in emissions trading programs means that a firm holds enough permits to cover its emissions, a risk neutral competitive firm's marginal benefit of noncompliance is what it has to spend for permits to make sure it is compliant, that is, the prevailing permit price. Thus, a firm's compliance decision is made by comparing the permit price with the marginal expected penalty for emissions in excess of permits. Since this marginal benefit-cost comparison does not depend on anything unique to a particular firm, the compliance decision is independent of any exogenous firm characteristic.

This result contrasts sharply with the effects of firm-level characteristics on compliance with command-and-control standards. A risk neutral firm's decision about whether to comply with a fixed emissions standard should be determined by the relationship between its marginal benefit from increased emissions and the marginal expected penalty it faces for violating the standard. Consequently, firms with higher marginal benefits of emissions or who face stricter standards will have a greater incentive to be noncompliant. In this way, firm-level characteristics are

\footnotetext{
${ }^{1}$ In the case of uniformly mixed pollutants, this is equivalent to seeking to reduce the environmental damage from noncompliance. If pollution is not uniformly mixed, then regulators may wish to target enforcement effort at firms that have greater impacts on environmental quality. We do not address this possibility in this paper.
} 
important determinants of compliance with fixed standards (Garvie and Keeler [12]). A recent paper by Gray and Shadbegian [13] finds strong support for this conclusion in their analysis of compliance behavior by pulp and paper manufacturers.

Our experimental results are largely consistent with the general hypothesis that individual compliance decisions in emissions trading programs are independent of differences in firms' characteristics, but not completely so. We find that individual violations are independent of parametric differences in firms' marginal benefits from emissions. However, individual violations are not independent of the initial allocation of permits. What appears to matter most about the initial allocation of permits is how it determines who will sell permits and who will buy them. We find that those subjects who are predicted to buy permits tend to have higher violation levels than those who are predicted to sell permits. A closer look at this initial allocation effect reveals that, for experienced subjects, it is due to the greater tendency of some permit sellers to be fully compliant when theory predicts that all subjects would be noncompliant. However, there is no initial allocation effect on the violation levels of those who choose to be noncompliant as predicted. ${ }^{2}$ Thus, if these results hold in field settings with actual firms, experienced managers and seasoned traders, then a regulator may be motivated to target buyers of permits, because they will tend to be noncompliant more often than sellers.

However, the more economically defensible strategy is for a regulator to maximize the productivity of enforcement resources. We test whether the productivity of increased enforcement (either increased monitoring or increased penalties) in reducing individual violations varies according to differences in emissions benefits and initial allocations of permits, and find that the marginal productivity of enforcement is statistically independent of firm-

\footnotetext{
${ }^{2}$ We briefly explore several possible explanations for this initial allocation effect, including an endowment effect that generates a difference between subjects' willingness to pay for permits and their willingness to buy permits, market power on the part of permit sellers, and risk aversion. None of these explanations are satisfactory.
} 
specific characteristics. Thus, a regulator who wishes to maximize the productivity of enforcement resources has no theoretical or experimental justification for pursuing a targeted enforcement strategy.

We do not expect this "no-targeting" result to hold under fixed emissions standards. We ran a separate series of experiments that were identical to our market experiments, except that subjects could not trade their initial allocations of permits. The results of these experiments provide an empirical study of how different compliance behavior is under the two types of policies. Consistent with theoretical expectations (e.g., Garvie and Keeler [12]), subjects with higher marginal benefits from emissions had significantly higher violations and were much more responsive to increased enforcement. Thus, there is substantial justification for pursuing targeted enforcement strategies when firms face fixed emissions standards, but little reason to do so in emissions trading programs.

Although experimental techniques have been used to evaluate other policy initiatives, including some aspects of emissions trading programs (e.g., Cason [5], Cason and Plott [7], Ishikida et al. [17], Isaac and Holt [16]), these techniques have not yet been widely applied to issues of regulatory enforcement, much less to compliance behavior in emissions trading programs. ${ }^{3}$ However, laboratory experiments are particularly useful for an inquiry into the determinants of compliance in these programs because the opportunities for empirical analyses of compliance behavior in existing trading programs are limited at present. Many programs have achieved such high rates of compliance that there is simply not enough variation in compliance decisions to conduct meaningful econometric analyses. For example, the enforcement strategies of the Sulfur Dioxide Allowance Trading program and the RECLAIM program of southern

${ }^{3}$ By far, the bulk of experimental analyses of compliance and enforcement is in the area of income tax compliance. See Alm and McKee [1] and Torgler [33] for comprehensive surveys of this literature. 
California were clearly designed to achieve very high rates of compliance, and have been largely successful in doing so (Stranlund, Chávez, and Field [31]). Other emissions permit markets have not yet fully developed. This is the case for the emissions trading program for total suspended particulates in Santiago, Chile (Montero, Sanchez, and Katz [24]). In fact, because so few trades have taken place in this program, Palacios and Chávez [27] were forced to assume that sources in this program faced fixed standards to conduct an empirical analysis of their compliance behavior.

We are aware of only two papers that use laboratory experiments to examine compliance behavior in emission permit markets. Cason and Gangadharan’s [6] experiments involve emissions trading when emissions are stochastic, permits can be banked, and subjects are audited based on their past compliance history. This design allowed them to identify interesting interactions between random emissions shocks, permit banking, and compliance. Our approach is much simpler: emissions are deterministic, banking permits from one period to the next is not allowed, and audits are completely random with a known and constant probability. This approach allows us to generate fundamental results about the potential for targeted enforcement in emissions trading programs that Cason and Gangadharan do not consider.

Murphy and Stranlund [26] is closely related to our current work in terms of design, but has a different focus. That work considers the effects of changing enforcement strategies on the permit market, and in turn the indirect effects of enforcement on compliance behavior. Although identifying the direct and indirect market effects of enforcement is also important to us in this paper, Murphy and Stranlund do not examine how the marginal productivity of enforcement may vary across firms, and hence, they do not draw conclusions about whether targeted enforcement is appropriate in emission trading programs. In addition, their work focuses solely on imperfect compliance. We include treatments in which subjects are predicted to be perfectly compliant so 
that we can examine firm-level determinants of compliance over the full range of enforcement strategies, from weak enforcement with significant noncompliance to strong enforcement that is sufficient to induce perfect compliance. Finally, neither Cason and Gangadharan [6] nor Murphy and Stranlund [26] conduct experiments with fixed emissions standards to draw conclusions about how compliance decisions differ under market-based and command-and-control regulation.

\section{Hypotheses}

We designed our experiments to test fundamental hypotheses about the compliance behavior of firms under emissions trading and under fixed emissions standards. These hypotheses come from existing theoretical models, in particular Stranlund and Dhanda [32] in the case of emissions trading and Garvie and Keeler [12] in the case of emissions standards. We urge the reader to consult these papers for the detailed development of these hypotheses.

Consider a fixed number of risk neutral firms in a perfectly competitive emissions trading program. ${ }^{4} \mathrm{~A}$ firm's benefit from emissions is $b(q, \theta)$, which is strictly concave in the firm's emissions $q \cdot{ }^{5}$ Heterogeneity of the firms is captured by the parameter $\theta$. A total of $L$ emissions permits are distributed to the firms, free of charge. The firm receives $l^{0}$ permits initially, and

${ }^{4}$ It is important to note that the existing theoretical models of emissions trading can easily be applied to other tradable property rights programs. For example, recent papers by Hatcher [14] and Chávez and Salgado [8] are direct applications of the literature on compliance and enforcement of emissions trading to individual transferable fishing quotas. Thus the results of this paper apply more broadly than just emissions trading.

${ }^{5}$ Strictly speaking, the benefit function is a firm's profit net of the value of permit transactions and expected penalties. See Montgomery [25] for a demonstration of the concavity of profit in emissions for firms that are price-takers in input and output markets. Since the formulation of $b\left(q_{i}, \theta_{i}\right)$ is quite general, strict concavity can be guaranteed in many non-competitive settings as well. Many theoretical analyses model firms' abatement costs rather than benefits from emissions. We presented our subjects with benefit functions so we use them here to maintain consistency. There is no loss of generality in our approach. 
holds $l$ permits after trading in a compliance period is complete. Competitive behavior in the permit market establishes a constant price per permit $p$.

If a firm is noncompliant, then its emissions exceed the number of permits it holds and the magnitude of its violation is $v=q-l>0$. If the firm is compliant, $q-l \leq 0$ and $v=0$. To check for compliance, each firm is audited with a known probability $\pi$. A firm that is found to be in violation is assessed a penalty, $f(v, \phi)$. There is no penalty for a zero violation, but for positive violations, the penalty is positive, strictly increasing and strictly convex. An increase in the parameter $\phi$ increases both total and marginal penalties.

Assuming that each firm chooses positive emissions and permits and never overcomplies, then the firm's problem is to choose its emissions and violation level to minimize its expected net benefits, $b(q, \theta)-p\left(l-l^{0}\right)-\pi f(v, \phi)$, subject to $v=e-l \geq 0$. The following hypotheses follow from this model:

Hypothesis 1: Under a competitive emissions trading program, the violation levels of risk neutral firms are independent of differences in their benefits from emissions and their initial allocations of permits.

Hypothesis 2: Under a competitive emissions trading program, the marginal productivity of increased enforcement (either increased monitoring or increased penalties) on the violation levels of risk neutral firms is independent of differences in the firms' benefits from emissions and their initial allocations of permits. 
Stranlund and Dhanda [32] argue that the differences in the size of individual violations of risk neutral firms that trade permits competitively should be independent of differences in their benefits from emissions. This result holds because the permit price is what drives compliance decisions, and all firms face the same market price. Conceptually, therefore, there is no reason for regulators to believe that some firms will be more likely to be noncompliant or tend toward higher violations even though they may have very different emissions benefit functions or initial permit allocations. ${ }^{6}$ Hence, a regulator who is motivated to target enforcement resources to detect incidences of noncompliance or higher levels of violation cannot do so productively on the basis of firm-level characteristics.

On the other hand, a regulator who is motivated to direct enforcement effort to where it will be most productive in reducing aggregate violations will not necessarily care about individual violation levels, but rather will be focused on the marginal productivity of enforcement effort across firms. Since a firm's choice of violation is independent of its benefits from emissions and its initial allocation of permits, the marginal productivity of enforcement effort is independent of these parameters as well. The determination of the marginal productivity of enhanced enforcement is complicated somewhat by a unique feature of enforcing marketbased policies: enforcement will have a direct effect on individual violations, as well as an indirect effect through its impact on the equilibrium of the permit market. These effects work in opposite directions, but it easy to demonstrate that the direct effect of increased enforcement dominates the indirect price effect so that a general increase in monitoring or penalties leads to lower violations. Murphy and Stranlund [26] confirm this hypothesis in the laboratory.

\footnotetext{
${ }^{6}$ Compliance choices will not be independent of the initial allocation of permits or firms' benefits from emissions in the presence of market power (van Egteren and Weber [34], Malik [23], Chávez and Stranlund [9]), or transaction costs (Chávez and Stranlund [10]).
} 
Matters are very different for firms that face fixed emissions standards. If the firm faces an emissions standard $s$, its violation is $v=q-s \geq 0$, and it chooses its violation to maximize $b(q, \theta)-\pi f(q-s, \phi)$, subject to $q-s \geq 0$.

Hypothesis 3: Under fixed emissions standards, the violation levels of risk neutral firms are higher for firms with higher marginal emissions benefits and/or lower emissions standards.

Hypothesis 4: Under fixed emissions standards, if firms' benefits from emissions and the penalty function are quadratic functions, then the marginal productivity of increased enforcement (either increased monitoring or increased penalties) on the violation levels of risk neutral firms is greater for firms with higher marginal emissions benefits and/or lower emissions standards.

Thus, with fixed emissions standards a regulator who is motivated to detect and penalize noncompliant firms, particularly those that tend toward higher violations, should target firms with higher benefits from emissions and/or lower standards. Contrast this to competitive emissions trading for which regulators cannot use differences in marginal emissions benefits or the initial allocation of permits to target noncompliant firms or those with higher violations.

In further contrast to permit markets, the marginal productivity of increased enforcement with standards is likely to depend on firms' benefits from emissions and their emissions standards. Although, in general, it is not possible to identify the firms for which a regulator's enforcement effort is more effective, if firms' benefits from emissions and the penalty function are quadratic, as we assume in our experimental design, then it is straightforward to show that the marginal productivity of increased monitoring in reducing violations is greater for firms with 
higher marginal emissions benefits or that face lower standards. The same holds for the marginal productivity of increased penalties. Thus, to use enforcement resources most effectively, a regulator is justified in targeting firms with higher marginal emissions benefits or lower standards.

\section{Experimental Design and Procedures}

\subsection{Experiment design}

The experiments were designed to test our hypotheses about the relationships between individual firm characteristics and violation choices, but the subjects were placed in a more neutral environment. We framed the experiments as a production decision in which permits conveyed a license to produce, rather than an emissions decision, to avoid introducing potential biases due to individual attitudes about the environment or emissions trading.

During each period of the experiment, subjects simultaneously chose to produce units of a fictitious good and traded in a market for permits that conveyed the right to produce.

Participants could produce as much as they wished (up to a capacity constraint) regardless of the number of permits they owned. However, at the end of the period, each individual was audited with a known, exogenous probability. If an individual was audited and found to be noncompliant (i.e., total production exceeded permit holdings), then a penalty was applied.

Subjects received a benefit from their choice of production, $q$, which was generated from a linear marginal benefit function, $b^{\prime}(q)=18-\theta q$. Each experiment had eight subjects divided evenly into two types; subjects were randomly assigned a type. Subjects with a high marginal benefit function $\left(\theta_{H}=1\right)$ also had a greater production capacity of 17 units. Subjects with a low marginal benefit function ( $\theta_{L}=2$ ) could produce up to 8 units. Production was constrained to be 
a whole number. We denote subjects with high marginal production benefits as $H i g h M B$ subjects, and subjects with low marginal production benefits as $L o w M B$ subjects.

The treatment variables in this paper are the probability of an audit, the marginal penalty function, the initial permit allocation, and the total supply of permits. Table 1 summarizes the experimental design. Each of the twelve market treatments was repeated three times. Although our main focus is on compliance behavior in permit markets, we also ran several experiments in which subjects faced fixed standards to compare compliance behavior under emissions trading and emissions standards. The nine standards treatments are shown at the bottom of Table 1 . $<$ INSERT TABLE $1>$

To be compliant in the market experiments, subjects were required to possess sufficient permits, $l$, to cover their production. Limiting the total number of permits imposed an aggregate production standard, $L$. We consider two aggregate standards. In the low aggregate standard experiments ( $L_{L}=28$ ), denoted LowStandard, each of the four HighMB subjects was initially allocated $l^{0}=3$ permits, and the four $\operatorname{LowMB}$ subjects were each given four permits. We call this the (nearly) uniform initial allocation. In the high aggregate standard experiments ( $L_{H}=56$ ), denoted HighStandard, there were two different initial allocations of permits. With a uniform initial allocation, each of the eight subjects in an experiment started with seven permits. With a non-uniform initial allocation, the $\operatorname{HighMB}$ subjects began with $l^{0}=13$ permits, and the LowMB subjects had a single permit. Reallocating the initial allocation of permits in this way changes the prediction about which subjects would sell permits and which would buy permits and allows us to avoid confounding a firm's benefits from emissions with its status as a predicted buyer or seller of permits. In the competitive equilibrium, the $L o w M B$ subjects would be the net 
sellers of permits with the uniform initial allocation, and net buyers of permits when the initial allocation is nonuniform.

To check for compliance, each subject's record was examined with a known probability $\pi$. If a subject was audited and found to be non-compliant, that is $q>l$, then she was assessed a penalty that was generated from a linearly increasing marginal penalty function, $f^{\prime}(q-l)=F+\phi(q-l)$. By changing the parameters of the marginal expected penalty function, $\pi f^{\prime}(q-l)=\pi[F+\phi(q-l)]$, we developed four enforcement strategies, which we label High, $\operatorname{Medium}\left(\pi_{H}\right)$, Medium $\left(\pi_{L}\right)$, and Low. ${ }^{7}$ The High enforcement strategy involved a high audit probability and a high marginal penalty function $\left(\pi_{H}=0.70, F=17.5, \phi=1.43\right)$. All High marginal expected penalty treatments were parameterized to induce perfect compliance by risk neutral agents. With the high aggregate standard, however, the incentives for perfect compliance were much stronger. For the other three levels of enforcement, all risk neutral subjects should choose to be noncompliant. The treatments $\operatorname{Medium}\left(\pi_{H}\right)$ and $\operatorname{Medium}\left(\pi_{L}\right)$ involved the same marginal expected penalties, but Medium $\left(\pi_{H}\right)$ had a higher monitoring probability and a relatively low marginal penalty function $\left(\pi_{H}=0.70, F=6, \phi=1.43\right)$, whereas $\operatorname{Medium}\left(\pi_{L}\right)$ had a lower monitoring probability and a higher marginal penalty function $\left(\pi_{L}=0.35, F=12, \phi=\right.$ 2.90). Our intention here was to examine whether the subjects reacted differently to monitoring and penalties. ${ }^{8}$ The Low marginal expected penalty treatments had the weakest enforcement

7 The enforcement parameters were the same for each subject type with the exception that, since LowMB subjects could only produce up to eight units, only the first eight steps of the penalty schedule were displayed for them.

${ }^{8}$ We are aware of only a few experimental studies that examine the relative importance of monitoring vs. penalties. Anderson and Stafford [2] examined this issue in the context of compliance to quotas for contributing to a public good and found that punishment severity had a larger effect on compliance than audit frequency. This result is consistent with risk averse subjects (Becker [3]). An early study by Friedland et al. [11] found the same result in a tax compliance experiment. With a unique design aimed at antitrust compliance, Block and Gerety [4] found that university students were more responsive to penalties than to monitoring frequency, but that incarcerated criminals were more responsive to monitoring than to the severity of punishments. 
strategy with the low monitoring probability and a low marginal penalty function $\left(\pi_{L}=0.35, F=\right.$ 2, $\phi=2.90)$. Enforcement parameter values were chosen, in part, so that the expected marginal penalty functions are parallel to each other-each has a slope of about one.

\subsection{Experiment procedures}

Participants were recruited from the student population at the University of Massachusetts, Amherst. Subjects were paid \$7 for agreeing to participate and showing up on time, and were then given an opportunity to earn additional money in the experiment. These additional earnings ranged between $\$ 5.68$ and $\$ 17.49$, with a mean of $\$ 13.67(\sigma=1.46)$. Earnings were paid in cash at the end of each experiment. Each experiment lasted about 2 hours.

The experiments were run in a computer lab using software designed specifically for this research. To familiarize subjects with the experiments, we ran a series of training experiments. In the first stage of the trainers, students read online instructions that included interactive questions to ensure that they understood the instructions before proceeding. After everyone had completed the instructions and all questions were answered, the training experiment began. These practice rounds contained all the same features as the "real data” experiments with the exception that we used a different set of parameters. The data from the trainers were discarded.

For the real data sessions, we recruited participants from the pool of trained subjects. Subjects were allowed to participate in multiple sessions, which allows us to test for experience effects. A total of 176 subjects participated in 36 eight-person permit market experiments (12 treatments, three sessions per treatment). ${ }^{9}$ Prior to the start of the real data experiments, subjects

\footnotetext{
9 Because subjects were allowed to participate in multiple sessions, the number of unique participants is less than
} the total required. 
were given a summary of the experiment instructions. ${ }^{10}$ The experimenter read these instructions aloud and answered any questions. Each subject was given a calculator, a pencil and paper. Each experiment consisted of 12 identical rounds. At the start of each period, the eight subjects were each given an initial allocation of permits and \$10 in experimental cash.

A unique feature of our experiments is that the production decisions and permit market trading were unbundled into two separate, but simultaneous, activities. We did this to allow for the possibility that the production levels and permit holdings could differ, thereby introducing a compliance decision. During the period and concurrent with the production decision, subjects were able to alter their permit holdings by trading in a continuous double auction. In the auction, individuals could submit bids to buy or asks to sell a single permit. The highest bid and lowest ask price were displayed on the screen. A trade occurred whenever a buyer accepted the current ask or a seller accepted the current bid. After each trade, the current bid and ask were cleared and the market opened for a new set of bids and asks. The trading price history was displayed on the screen.

Each period lasted a total of five minutes. The permit market was open for the entire period, but production had to be completed in the first four minutes. The one-minute reconciliation period gave subjects a final opportunity to adjust their permit holdings. After each period ended, random audits were conducted and penalties were assessed. All information relating to audit outcomes was private.

Although our main focus is on compliance behavior in permit markets, we also conducted a separate series of experiments with a fixed standard using only the uniform initial permit allocation (see Table 1). A total of 132 subjects participated in the standards experiments and

\footnotetext{
${ }^{10}$ The complete instructions, along with the summary are available online at http://www.umass.edu/resec/faculty/murphy/research.html.
} 
subjects were allowed to participate in multiple sessions. The structure of these standards experiments were the same as their market counterparts, except that the permits were not tradable. Therefore, the initial permit allocation became the fixed standard.

Our designs yield observations on permit prices in the market experiments, and individual compliance decisions in both the market and standards experiments. Giving subjects different production benefit schedules and initial allocations of permits allow us to test for the impacts of these differences on individual violations under both emissions trading and fixed emissions standards (Hypotheses 1 and 3). Moreover, varying the enforcement parameters allows us to test whether the marginal productivity of enforcement is sensitive to differences in production benefits and initial permit allocations under emissions trading and emissions standards (Hypotheses 2 and 4).

\section{Results}

We begin our analysis of the market results with a discussion of general patterns in the permit price and individual violations. We use some of these patterns to motivate our econometric model specifications when estimating these variables. The econometric analysis is used to test our specific hypotheses. Because our theoretical development suggests that an individual's violation decision is conditioned on the permit price, we first estimate this price and then use the estimated price as an instrumental variable when modeling violation choices. Because individuals make decisions in multi-round experiments, we control for repeated measures using random effects models. We omit the data from the first period to minimize the effects of learning and price discovery. This omission does not have a qualitative effect on any of our conclusions. 
In addition to the data reported in this paper, we also ran a separate series of "perfect compliance" experiments for the low and high standards with uniform permit allocations. These experiments were identical to those described in this paper, except that production was assumed to exactly equal the final permit balance; that is, noncompliance was not allowed and audits were unnecessary. This is essentially a standard continuous double auction for permits. As expected, observed prices and quantities in these experiments quickly converged to the competitive equilibrium. Therefore, we are confident that any deviations from the competitive prediction in the discussion below reflect treatment effects related to the compliance decision and are not artifacts of the subject pool or experimental design. ${ }^{11}$

\subsection{General patterns in market experiments}

Table 2 presents some summary statistics of permit prices. Mean and median prices tend to be higher than the competitive equilibrium prediction, but they move as expected: prices tend to be higher when the aggregate standard is reduced and when the marginal expected penalty is increased. However, note that with the HighStandard treatments, for a given marginal expected penalty, mean and median prices are higher for the nonuniform initial allocation of permits. This, of course, is not consistent with the conventional hypothesis that individual behavior and market outcomes under competitive emissions trading programs are independent of the initial allocation of permits. <INSERT TABLE 2>

Table 3 presents some summary statistics for individual violations. Mean and median violations also move as expected. Given the aggregate standard, they tend to be lower with higher marginal expected penalties, and given the enforcement strategy, they tend to be lower

\footnotetext{
${ }^{11}$ The results from our "perfect compliance" experiments are available upon request.
} 
with the high standard. Conceptually, this latter result is due to the lower permit prices resulting from this higher standard. <INSERT TABLE 3>

We observe an interesting pattern in mean and median violations that plays an important role in how we analyze and interpret violation choices. The competitive equilibrium prediction is that individual violations should be uniform across subjects in each treatment. However, mean and median violation levels clearly differ by subject type, but whether HighMB subjects tend toward higher or lower violations than $L o w M B$ subjects appears to depend on the initial allocation of permits. In particular, consider the eight uniform allocation treatments. The $H i g h M B$ subjects are predicted to be the net buyers of permits in these treatments, and they clearly tend toward higher violations than the $L o w M B$ subjects. On the other hand, for the four nonuniform allocation treatments, the $L o w M B$ subjects are predicted to be the permit buyers, and they are the ones that tend toward higher violations. It appears that the differences in violations by subject type may be determined in part by how the initial allocation of permits determines whether subjects will be net buyers or sellers of permits. This speculation is easily tested and we will do so shortly.

\subsection{Market regression results and tests of hypotheses}

Table 4 presents the results of a linear random effects model of the permit price. The dependent variable is the price of each trade in period $t=2, \ldots, 12$ of group $j=1, \ldots, 36$. The marginal expected penalty, the aggregate standard, and the initial allocation are modeled as fixed effects. The price estimation results in Table 4 confirm the impressions we reached by comparing average prices across treatments. The coefficients for the three marginal expected penalties are increasing, indicating that, under the high standard, increased enforcement puts upward pressure on the equilibrium price. Moreover, the two MediumMEP coefficients are statistically 
indistinguishable from each other. The coefficient on LowStandard is positive and significant, indicating the unsurprising result that permit prices increase as the supply of permits is reduced. It is straightforward to demonstrate that, under the LowStandard, the permit price increases as enforcement is increased from LowMEP to Medium $\left(\pi_{H}\right) M E P$ and then to HighMEP. However, note the positive and significant coefficient for the interaction between LowStandard and $\operatorname{Medium}\left(\pi_{L}\right) M E P$. This is capturing the extraordinarily high price in this treatment that is evident in Table 2. Finally, the NonUniform coefficient is positive and significant, as we expected from our perusal of the average price results, even though theory predicts otherwise. $<$ INSERT

\section{TABLE 4>}

Table 5 presents the results of two linear random effects models for individual violations. Model 1 estimates the effects of the treatment variables on violations. Model 2 adds the interaction effects needed to test Hypothesis 2, which requires that we capture all possible combinations of subject type and treatments in Table 2. Using an instrumental variable approach, PriceHat is the estimated price from the model in Table 4. HighMB is a fixed effect that equals one for subjects with the high marginal benefits. NetSeller is a fixed effect that equals one if the subject is predicted to be a net seller (i.e., HighMB subjects for the nonuniform allocations and LowMB subjects for the uniform allocations). In Model 1 note the negative and significant impact of enforcement, and the positive and significant impact of price. Moreover, the coefficients for Medium $\left(\pi_{H}\right) M E P$ and Medium $\left(\pi_{L}\right) M E P$ are not statistically different from each other at conventional levels of significance $(p=0.14)$. This indicates that the subjects did not react differently to increased monitoring or increased penalties that resulted in the same expected marginal penalty function. ${ }^{12}$

\footnotetext{
${ }^{12}$ We find the same result in our fixed standards experiments. This result contrasts with other experimental studies that examine the relative effects of monitoring and penalties in other settings (see footnote 8).
} 
$<$ INSERT TABLE 5>

While comparing mean and median violations across treatments, we suggested that differences in violations by subject type may be determined in part by how the initial allocation of permits determines whether subjects will be net buyers or sellers of permits. This is confirmed by the estimation results. In Model 1 , the NetSeller coefficient is negative $(-0.68)$ and significant. Although NetSeller is not significant in Model 2, a test of the joint hypothesis that NetSeller and the four terms interacted with NetSeller are all equal to zero is rejected (Wald $\chi^{2}(5)$ $=28.9, p=0.00)$. On the other hand, the coefficient on HighMB is small and not statistically significant in both Models 1 and $2 .^{13}$

Hypothesis 1 asserts that individual violations are independent of any subject-level characteristic. Our tests of this hypothesis are mixed. We have strong support for the hypothesis that violations are independent of differences in subjects’ marginal production benefits. However, individual violations are not independent of how the initial allocation of permits determines which subjects will sell permits and which will buy them. We will examine this latter effect more closely in the next subsection.

Although we find that permit buyers tend to have greater violation levels, it does not necessarily follow that a regulator who wishes to direct his enforcement effort to where it is most productive should target these firms. The estimates of the marginal productivity of enforcement in Table 6 reflect the sensitivity of violation choices by subject type to changes in enforcement pressure for a given aggregate standard and initial permit allocation. The values in the HighMB and $L o w M B$ columns are the estimated marginal changes in individual violations as enforcement

\footnotetext{
${ }^{13}$ With Model 2, each of the four interaction terms containing HighMB is not statistically significant. We also fail to reject the joint hypothesis that $H i g h M B$ and these four interaction terms are all equal to zero (Wald $\chi^{2}(5)=$ $0.34, p=0.997)$.
} 
is increased. Of course, these marginal effects have to include both the direct effects of enforcement and the indirect effects from changes in the permit price. Letting $\Delta E$ denote a change in enforcement, given an aggregate standard and initial allocation of permits, we calculated $\Delta v / \Delta E+(\Delta v / \Delta p)(\Delta p / \Delta E)$ for both the LowMB and HighMB firms for each increase in enforcement, aggregate standard, and initial allocation of permits. $\Delta v / \Delta E$ is the direct effect of the change in enforcement, while $(\Delta v / \Delta p) \times(\Delta p / \Delta E)$ is the indirect price effect. Values for $\Delta v / \Delta E$ and $\Delta v / \Delta p$ were calculated using Model 2 in Table 5, and $\Delta p / \Delta E$ was calculated using the price equation in Table 4. $<$ INSERT TABLE 6>

The last column of Table 6 contains the $p$-values for the tests of the hypothesis that the marginal productivity of enforcement is equal across subject types. ${ }^{14}$ Since none of the differences in marginal productivities between subject types are statistically significant, we have strong support for Hypothesis 2-the marginal productivity of enforcement is independent of differences in subjects' benefits and initial allocation of permits. This suggests the strong policy recommendation that regulators who seek to direct enforcement effort to where it is most productive do not have a theoretical or empirical justification for doing so on the basis of firmlevel characteristics.

\subsection{The initial allocation effect on individual violations}

The one result that is not consistent with the theory of compliance behavior by risk neutral firms in a competitive tradable rights program is that net buyers of permits tend toward larger violations than net sellers. It is worth exploring this result a bit more thoroughly.

\footnotetext{
${ }^{14}$ Although Table 6 compares subjects based on marginal benefits, the results would be identical if we instead compared them based on whether they were predicted to be net sellers or buyers. This is because all HighMB subjects are net buyers with a uniform allocation and net sellers with a nonuniform allocation (the reverse is true for $L o w M B$ subjects).
} 
We begin by noting that the initial allocation effect is limited to only a subset of our results. There is no initial allocation effect for individual choices of production in our perfect compliance experiments in which violations are not possible. Moreover, there is no initial allocation effect in our HighMEP treatments, which were designed to induce perfect compliance from risk neutral subjects. Instead, this effect is limited to those treatments that were designed to induce a significant amount of noncompliance, i.e., the $\operatorname{Medium}\left(\pi_{L}\right)$, Medium $\left(\pi_{H}\right)$, Low MEP treatments. Therefore, the initial allocation effect we observe is limited to those situations involving lessthan-perfect enforcement for which we expect a significant amount of noncompliance. We reiterate that the initial allocation has no effect on the marginal productivity of enforcement.

Even though theory predicts that all subjects in the $\operatorname{Medium}\left(\pi_{L}\right), \operatorname{Medium}\left(\pi_{H}\right), \operatorname{Low} M E P$ treatments would always choose to be noncompliance, a significant number chose to be compliant. Therefore, it is worth examining whether the initial allocation effect is different for those that chose to comply when we did not expect them to and those who chose not to comply as predicted. At the same time, List [20] suggests that endowment effects in markets tend to disappear with experienced subjects. Because subjects could participate in more than one of our experiments, we can examine how the initial allocation effect is affected by subjects' experience with our experiments.

To investigate the effects of experience, we created two additional dummy variables: ExperiencedNetSeller equals one for those subjects who participated in more than one experiment and were assigned roles in which they were predicted to be net sellers of permits, and ExperiencedNetBuyer is defined similarly for those predicted to be net buyers. To distinguish between compliant and noncompliant subjects we estimated a random effects logit model in which the dependent variable equals one if an individual was noncompliant; the independent 
variables were the same as in Model 1 of Table 5 with the addition of the two experience dummy variables. ${ }^{15}$ The results clearly indicate that the initial allocation effect persists for both experienced and inexperienced subjects $(p=0.00)$ and that the probability of a violation is lower for net sellers. However, when we estimate a linear random effects model of violations conditioned on the decision to be noncompliant, the initial allocation effect disappears for experienced subjects—-there is no statistically significant difference between the violations of experienced buyers and experienced sellers $(p=0.76)$. Thus, with experienced subjects, the initial allocation effect is only present in the choice of whether to be compliant, and not in the violation choices of those who chose to be noncompliant.

Therefore, if the initial allocation effect holds in field settings, then a regulator may be motivated to target buyers of permits, because they will tend to be noncompliant more often than sellers. Our view, however, is that the allocation effect matters very little, because the regulatory objective of detecting firms that are more likely to be noncompliant is inferior to the objective of maximizing the productivity of enforcement resources. On this matter, our results are unequivocal—-there is simply no justification for targeted enforcement.

Nevertheless, we wonder what could explain the initial allocation effect we observe. Let us briefly discuss three of the most obvious possibilities, none of which, however, provide satisfactory explanations. One possibility is an endowment effect that has been documented in a number of experimental settings (for a review see Kahneman, Knetsch and Thaler [18]). The endowment effect suggests that people place a higher value on goods they possess than on those they do not. That net sellers of permits in our experiments tended to have lower violations than buyers could be due to them placing a higher value on the permits they hold than one would

\footnotetext{
${ }^{15}$ Results available upon request.
} 
expect in a competitive equilibrium. This is consistent with the higher permit prices we observe and with the differences in violation choices between sellers and buyers in the Medium and Low marginal expected penalty treatments. However, if the endowment effect drives results in these treatments, it should also be present in our perfect compliance and HighMEP treatments, but it is not.

Another possibility is that net sellers of permits were able to exercise some degree of market power by holding on to more permits than in a perfectly competitive setting in order to push the permit price up. In fact, permit sellers did hold on to more permits than expected, and equilibrium permit prices were usually higher than expected. Conceptually, firms with market power that sell permits will tend to have lower violations than firms that buy permits (van Egteren and Weber [34]; Malik [23]; Chávez and Stranlund [9]). The problem with this explanation is that if market power explains the difference between the compliance choices of sellers and permits, we should also observe evidence of market power in our perfect compliance and HighMEP experiments, but we do not. If market power is the reason for the initial allocation result, then it must be possible that market power can arise in permit markets solely because of imperfect enforcement. It is not clear, however, why this would occur.

A final possible explanation for our initial allocation effect is predominant risk aversion in our subject pool. Certainly higher-than-predicted permit prices and lower-than-predicted levels of violation are consistent with risk aversion. In the published theoretical literature on compliance and enforcement of emissions trading only Malik [21] allows for non-neutral risk preferences, but he does not provide clear predictions of the qualitative impacts of firm characteristics on violation levels. Our experience suggests that specific predictions about these effects require severely limiting assumptions about agents' utility functions, in particular on 
whether a subject's utility functions exhibit constant, increasing, or decreasing absolute risk aversion (Stranlund [29]]). Moreover, if risk aversion implies that violation choices are dependent on the initial allocation of permits, then risk aversion would also imply that violations are dependent on subjects' benefits from production. Of course, we find that violation choices are independent of their production benefits. We have to conclude therefore, that risk aversion is not likely be an adequate explanation for our finding that net buyers of permits tend to be noncompliant more often than net sellers. ${ }^{16}$

\subsection{Standards}

Finally, let us turn to our fixed-standards experiments. Table 7 presents summary statistics for our fixed standards experiments with a uniform allocation of both low and high aggregate standards; we did not conduct any nonuniform allocation treatments. ${ }^{17}$ Recall that these standards experiments were identical to the permit market experiments, except that subjects were not able to trade their initial permit allocation. As predicted, HighMB subjects tended to have greater violation levels. The estimation results in Table 8 confirm this: the coefficient for HighMB subjects is positive (2.00) and highly significant. Moreover, the negative and significant coefficient for HighStandard (-0.94) indicates that individual violation levels tend to decrease as the standard is relaxed. Therefore, we have strong support for Hypothesis 3 and the enforcement implication that a regulator who is motivated to find and penalize firms with higher

\footnotetext{
${ }^{16}$ Interestingly, there may be a conceptual justification for our focus on risk neutrality. Rabin [28] has demonstrated that expected utility theory implies that people are approximately risk neutral when stakes are small, such as in our laboratory setting. On the other hand, experiments to elicit risk attitudes by Holt and Laury [15] suggest that most subjects are risk averse over small payoffs.

${ }^{17}$ This implies that we have one low and one high individual standard for both HighMB and LowMB subjects.
} 
violations to fixed emissions standards may be justified in targeting firms with higher marginal emissions benefits and lower standards. ${ }^{18}<$ INSERT TABLE 7>

We use the interaction effects of Model 2 in Table 8 to test for differences in the marginal productivity of enforcement. Similar to Table 6 for the case of permit trading, Table 9 includes the marginal productivity of enforcement under fixed standards and presents the results of tests for the equality of these values across subject types. Hypothesis 4 posits that violations of subjects with higher marginal benefits will be more responsive to changes in enforcement. This is true with our experimental design except in two cases. With a low standard, our prediction is that the change from the low marginal expected penalty to either of the medium marginal expected penalties has the same two unit reduction in violations for both subject types (see Table 7); this is simply an artifact of the experimental design, in particular that production choices are discrete. As expected, when enforcement changes from Low to Medium $\left(\pi_{H}\right)$ there is not a statistically significant difference in the marginal productivity of this change across subject types ( $p=0.76)$. However, there is the unanticipated significant difference in marginal productivities when enforcement changes from Low to Medium $\left(\pi_{L}\right)(p=0.02)$. More to the main point of Hypothesis 4, however, we find that marginal productivity of enforcement is significantly higher for the HighMB subjects for six of the eight cases in which we expect to observe this difference. $<$ INSERT TABLE $8><$ INSERT TABLE 9>

Hypothesis 4 also posits that the marginal productivity of increased enforcement is higher when individual standards are lower. Observe in Table 9 that for each subject type the effect of each change in enforcement is greater when they face the low standard. However, these

\footnotetext{
${ }^{18}$ As in the market experiments, the coefficients for Medium $\left(\pi_{H}\right) M E P$ and Medium $\left(\pi_{L}\right) M E P$ in Model 1 in Table 8 are not statistically different from each other at conventional levels of significance $(p=0.29)$. Again, the subjects in the fixed standards experiments did not react differently to increased monitoring or increased penalties that resulted in the same expected marginal penalty function.
} 
differences are statistically significant in only two of the five comparisons for the $\operatorname{HighMB}$ subjects, and in only one of the five comparisons for the LowMB subjects.

Although our results concerning Hypothesis 4 are mixed, we do have strong support for the policy recommendation that, under fixed standards, regulators who are motivated to direct their enforcement resources to where they will be most effective are justified in targeting firms with higher marginal emissions benefits. For the purposes of this paper, however, the most important message is that while firm-level characteristics are important determinants of the effectiveness of enforcement under command-and-control standards, the marginal productivity of enforcement does not depend on these characteristics under a competitive emissions trading program.

\section{Conclusions}

Compliance behavior in emissions trading programs is fundamentally different from compliance behavior under emissions standards. Conceptually, the compliance choices of risk neutral firms that operate in a competitive emissions trading program are independent of parametric differences in their benefits and their initial allocations of permits. Therefore, regulators have no justification for targeting their enforcement efforts either to find and punish those firms that tend to higher violations, or to maximize the productivity of their enforcement efforts in reducing aggregate violations. On the other hand, theory provides substantial justification for pursuing targeted enforcement strategies when firms face fixed emissions standards.

The results of our laboratory experiments generally support the conclusions of theoretical models of risk neutral compliance behavior in emissions trading programs, but not completely so. We find that the subjects' violations are independent of differences in their benefit functions, 
but their violations are not independent of how the initial allocation of permits determines which of them will sell permits and which will buy permits. When we limit our analysis to experienced subjects we find that this initial allocation effect is due to the tendency of permit sellers to be compliant more often than buyers when enforcement is not strong enough to induce full compliance by all individuals. Our more important result, however, is that individual differences in benefits or initial allocations of permits do not have a statistically significant impact on the marginal productivity of increased enforcement. Thus, under the important policy objective of maximizing the productivity of scarce enforcement resources, regulators have no theoretical or empirical justification for targeting firms based on their individual characteristics.

This “no-targeting” conclusion should not be applied when firms face fixed standards. Our experimental comparison of compliance behavior under emissions trading and emissions standards highlight substantial differences in behavior and, by implication, the design of enforcement strategies under these two policy instruments.

It is clear that if emissions trading programs are to fulfill their theoretical promise of costeffective pollution control, they must be enforced well. Designing appropriate enforcement strategies requires a theoretically and empirically balanced understanding of compliance behavior in these programs. While the theory of compliance and enforcement of emissions trading programs is well advanced, there are few empirical analyses of the fundamental results of this literature. The opportunities for analyses of compliance behavior in existing emissions trading programs are severely limited at present. Thus, further experimental analyses, like that contained in this paper, will lead to a better understanding of how market-based environmental policies should be designed, implemented, and managed to meet environmental quality goals cost-effectively. 


\section{Acknowledgements}

Primary funding for this research was provided by the U.S. EPA - Science to Achieve Results (STAR) Program grant \#R829608. Additional support was provided by the Cooperative State Research Extension, Education Service, U. S. Department of Agriculture, Massachusetts Agricultural Experiment Station, and the Department of Resource Economics under Project No. MAS00871, and by the Center for Public Policy and Administration, University of Massachusetts-Amherst. Maria Alejandra Velez, Carrie Puglisi and Maria Claudia Lopez provided outstanding research assistance. Glenn Caffery programmed the software for this project. Wendy Varner provided valuable administrative support. We are also grateful to Julie Hewitt for useful comments on an earlier draft of this work. The authors take full responsibility for any errors or omissions. 


\section{References}

[1] J. Alm and M. McKee, Extending the lessons of laboratory experiments on tax compliance to managerial and decision economics, Managerial Dec. Econ. 19, 259-275 (1998), doi: 10.1002/(SICI)1099-1468(199806/08)19:4/5<259.

[2] L. R. Anderson and S. L. Stafford, Punishment in a regulatory setting: experimental evidence from the VCM, J. Regul. Econ. 24, 91-110 (2003), doi: 10.1023/A:1023952115422.

[3] G. S. Becker, Crime and punishment: an economic approach, J. Polit. Economy 76, 169217 (1968).

[4] M. K. Block and V. E. Gerety, Some experimental evidence on difference between student and prisoner reactions to monetary penalties and risk, J. Legal Stud. 24, 123-138 (1995).

[5] T. N. Cason, An experimental investigation of the seller incentives in the EPA's emissions trading auction, Amer. Econ. Rev. 85, 905-922 (1995).

[6] T. N. Cason and L. Gangadharan, Emissions variability in tradable permit markets with imperfect enforcement and banking, J. Econ. Behav. Organ., forthcoming (2006), doi:10.1016/j.jebo.2005.02.007.

[7] T. N. Cason and C.R. Plott, EPA's new emissions trading mechanism: a laboratory evaluation, J. Environ. Econ. Manage. 30, 133-160 (1996), doi:10.1006/jeem.1996.0010.

[8] C. A. Chávez and H. Salgado, Individual transferable quota markets under illegal fishing, Environ. Resource Econ. 31, 303-324 (2005), doi: 10.1007/s10640-005-1543-6.

[9] C. A. Chávez and J. K. Stranlund, Enforcing transferable permit systems in the presence of market power, Environ. Resource Econ. 25, 65-78 (2003), doi: 10.1023/A:1023646414602.

[10] C. A. Chávez and J. K. Stranlund, Enforcing transferable permit systems in the presence of transaction costs, Working Paper No. 2004-3, Department of Resource Economics, University of Massachusetts, Amherst (2004).

[11] N. Friedland, S. Maital and A. Rutenberg, A simulation study of income tax evasion, $J$. Public Econ. 10, 107-116 (1978).

[12] D. Garvie and A. Keeler, Incomplete enforcement with endogenous regulatory choice, $J$. Public Econ. 55, 141-162 (1994).

[13] W. Gray and R. Shadbegian, When and why do firms comply? Paper mills in the 1980's, Law and Policy 27, 238-261 (2005).

[14] A. Hatcher, Non-compliance and the quota price in an ITQ fishery, J. Environ. Econ. Manage. 49, 427-436 (2005), doi:10.1016/j.jeem.2004.06.002.

[15] C. A. Holt and S.K. Laury, Risk aversion and incentive effects, Amer. Econ. Rev. 92, 1644-55 (2002), doi: 10.1257/000282802762024700.

[16] R. M. Isaac and C. Holt, Research in experimental economics: emissions permit experiments, Vol. 7. JAI Press, Stamford, CT (1999). 
[17] T. Ishikida, J. Ledyard, D. Porter and M. Olson, Implementation of a combinatorial market. The experiments behind the automated-environmental credit exchange (ACE), Working paper, California Institute of Technology, Pasadena, CA (1998).

[18] D. Kahneman, J. L. Knetsch, and R.H. Thaler, Anomalies: the endowment effect, loss aversion, and status quo bias, J. Econ. Perspect. 5, 193-206 (1991).

[19] A. Keeler, Noncompliant firms in transferable discharge permit markets: some extensions, J. Environ. Econ. Manage. 21, 180-189 (1991), doi:10.1016/0095-0696(91)90041-G.

[20] J. A. List, Does market experience eliminate market anomalies?, Quart. J. Econ. 118, 4171 (2003).

[21] A. S. Malik, Markets for pollution control when firms are noncompliant, J. Environ. Econ. Manage. 18, 97-106 (1990), doi:10.1016/0095-0696(90)90041-V.

[22] A. S. Malik, Enforcement cost and the choice of policy instruments for controlling pollution, Econ. Inquiry 30, 714-721 (1992).

[23] A. S. Malik, Further results on permit markets with market power and cheating, $J$. Environ. Econ. Manage. 44, 371-90 (2002), doi:10.1006/jeem.2001.1216.

[24] J.-P. Montero, J. M. Sanchez and R. Katz, A market-based environmental policy experiment in Chile, J. Law Econ. 45, 267-287 (2002), doi: 0022-2186/2002/4501$0010 \$ 01.50$.

[25] W. D. Montgomery, Markets in licenses and efficient pollution control programs, J. Econ. Theory 5, 395-418 (1972).

[26] J. J. Murphy and J. K. Stranlund, Direct and market effects of enforcing emissions trading programs: an experimental analysis, J. Econ. Behav. Organ., forthcoming (2006), doi:10.1016/j.jebo.2005.03.013.

[27] M. Palacios and C. Chávez, Determinants of compliance in the emissions compensation program in Santiago, Chile, Environ. Devel. Econ. 10, 453-483 (2005), doi: 10.1017/S1355770X05002299.

[28] M. Rabin, Risk aversion and expected-utility theory: a calibration theorem, Econometrica 68, 1281-1292 (2000), doi:10.1111/1468-0262.00158.

[29] J. K. Stranlund, Risk aversion and compliance in markets for pollution control, Working Paper, Department of Resource Economics, University of Massachusetts, Amherst (2006).

[30] J. K. Stranlund and C. A. Chávez, Effective enforcement of a transferable emissions permit system with a self-reporting requirement, J. Regul. Econ. 18, 113-131 (2000), doi: 10.1023/A:1008160317757.

[31] J. K. Stranlund, C. A. Chávez and B. Field, Enforcing emissions trading programs: theory, practice and performance, Policy Studies Journal 30, 343-361 (2002).

[32] J. K. Stranlund and K. K. Dhanda, Endogenous monitoring and enforcement of a transferable emissions permit system, J. Environ. Econ. Manage. 38, 267-282 (1999), doi:10.1006/jeem.1999.1092.

[33] B. Torgler, Speaking to theorists and searching for facts: tax morale and tax compliance in experiments, J. Econ. Surveys 16, 657-683 (2002). 
[34] H. van Egteren and M. Weber, Marketable permits, market power, and cheating, $J$. Environ. Econ. Manage. 30, 161-173 (1996), doi:10.1006/jeem.1996.0011. 


\section{Table 1. Experimental Design}

\section{Market Experiments}

Marginal Expected Penalty

Allocation

$\begin{array}{ll}\text { High } & \text { Low Standard, Uniform } \\ \text { Medium }\left(\pi_{H}\right) & \text { High Standard, Uniform } \\ \text { Medium }\left(\pi_{L}\right) & \text { High Standard, Non-uniform } \\ \text { Low } & \end{array}$

The twelve market treatments were constructed by interacting the four marginal expected penalties with the three allocations. Each treatment was repeated three times with eight participants per group.

\section{Standards Experiments}

Marginal Expected Penalty

High

Allocation

$\operatorname{Medium}\left(\pi_{H}\right)$

Low Standard, Uniform

$\operatorname{Medium}\left(\pi_{L}\right)$

High Standard, Uniform

Low

The eight standards treatments were constructed by interacting the four marginal expected penalties with the two allocations. Each treatment was repeated three times with eight participants per group. Data from one subject dropped from the standards experiment with the Low marginal expected penalty and Low Standard due to bankruptcy after 3 periods. 
Table 2. Permit Price Summary Statistics

\begin{tabular}{|c|c|c|c|c|c|}
\hline & $\begin{array}{c}\text { Marginal Expected } \\
\text { Penalty } \\
\end{array}$ & $\begin{array}{l}\text { Competitive } \\
\text { Equilibrium } \\
\end{array}$ & Mean & Median & $\begin{array}{l}\text { Standard } \\
\text { Deviation } \\
\end{array}$ \\
\hline \multirow{4}{*}{ 茪 } & High & $12-13$ & 12.57 & 12.68 & 0.95 \\
\hline & $\operatorname{Medium}\left(\pi_{H}\right)$ & \multirow{2}{*}{$8-8.20$} & 9.61 & 9.30 & 1.18 \\
\hline & $\operatorname{Medium}\left(\pi_{L}\right)$ & & 13.26 & 13.50 & 1.84 \\
\hline & Low & 6 & 8.11 & 7.90 & 1.55 \\
\hline \multirow{8}{*}{ 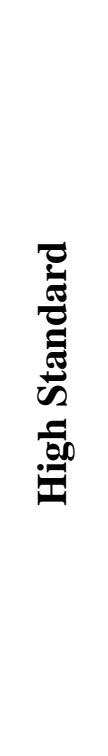 } & High & \multirow[b]{2}{*}{8} & 7.94 & 8.00 & 0.76 \\
\hline & $\begin{array}{l}\text { High } \\
\text { Nonuniform }\end{array}$ & & 9.74 & 9.00 & 2.40 \\
\hline & $\operatorname{Medium}\left(\pi_{H}\right)$ & \multirow{4}{*}{$6-6.20$} & 7.09 & 7.25 & 1.02 \\
\hline & $\begin{array}{l}\text { Medium }\left(\pi_{H}\right) \\
\text { Nonuniform }\end{array}$ & & 7.79 & 7.60 & 1.10 \\
\hline & $\operatorname{Medium}\left(\pi_{L}\right)$ & & 6.74 & 6.85 & 0.58 \\
\hline & $\begin{array}{l}\text { Medium }\left(\pi_{L}\right) \\
\text { Nonuniform }\end{array}$ & & 7.24 & 7.20 & 1.39 \\
\hline & Low & \multirow[b]{2}{*}{4} & 3.97 & 4.00 & 0.74 \\
\hline & $\begin{array}{l}\text { Low } \\
\text { Nonuniform }\end{array}$ & & 6.50 & 7.00 & 1.36 \\
\hline
\end{tabular}


Table 3. Summary Statistics for Individual Violations (Emissions Trading)

\begin{tabular}{|c|c|c|c|c|c|c|}
\hline & $\begin{array}{c}\text { Marginal } \\
\text { Expected Penalty }\end{array}$ & $\begin{array}{l}\text { Competitive } \\
\text { Equilibrium }\end{array}$ & Firm MB & Mean & Median & $\begin{array}{l}\text { Standard } \\
\text { Deviation } \\
\end{array}$ \\
\hline \multirow{8}{*}{ 草营 } & \multirow{2}{*}{ High } & \multirow{2}{*}{0} & High & 0.4 & 0 & 0.8 \\
\hline & & & Low & 0.2 & 0 & 0.5 \\
\hline & \multirow{2}{*}{$\operatorname{Medium}\left(\pi_{H}\right)$} & \multirow{4}{*}{3} & High & 3.1 & 3 & 1.0 \\
\hline & & & Low & 2.0 & 2 & 1.5 \\
\hline & \multirow{2}{*}{$\operatorname{Medium}\left(\pi_{L}\right)$} & & High & 1.9 & 1 & 2.0 \\
\hline & & & Low & 1.2 & 1 & 1.4 \\
\hline & \multirow{2}{*}{ Low } & \multirow{2}{*}{ (4 or 5$)$} & High & 3.7 & 3 & 2.0 \\
\hline & & & Low & 3.3 & 3 & 1.5 \\
\hline \multirow{16}{*}{ 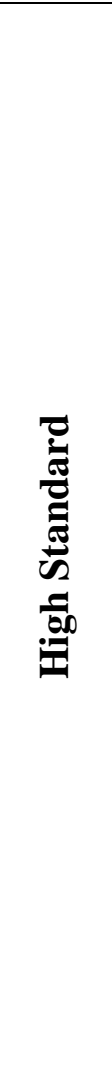 } & \multirow{2}{*}{ High } & \multirow{4}{*}{0} & High & 0.1 & 0 & 0.5 \\
\hline & & & Low & 0.1 & 0 & 0.4 \\
\hline & \multirow{2}{*}{$\begin{array}{l}\text { High } \\
\text { Nonuniform }\end{array}$} & & High & 0.1 & 0 & 0.4 \\
\hline & & & Low & 0.2 & 0 & 0.5 \\
\hline & \multirow{2}{*}{$\operatorname{Medium}\left(\pi_{H}\right)$} & \multirow{8}{*}{1} & High & 1.2 & 1 & 1.1 \\
\hline & & & Low & 0.7 & 0 & 1.3 \\
\hline & \multirow{2}{*}{$\begin{array}{l}\operatorname{Medium}\left(\pi_{H}\right) \\
\operatorname{Nonuniform}\end{array}$} & & High & 0.6 & 0 & 1.2 \\
\hline & & & Low & 1.3 & 1 & 1.2 \\
\hline & \multirow{2}{*}{$\operatorname{Medium}\left(\pi_{L}\right)$} & & High & 1.4 & 1 & 1.3 \\
\hline & & & Low & 0.8 & 0 & 1.5 \\
\hline & \multirow{2}{*}{$\begin{array}{l}\operatorname{Medium}\left(\pi_{L}\right) \\
\text { Nonuniform }\end{array}$} & & High & 0.8 & 0 & 2.3 \\
\hline & & & Low & 1.5 & 1 & 1.7 \\
\hline & \multirow{2}{*}{ Low } & \multirow{4}{*}{ (2 or 3$)$} & High & 3.6 & 3 & 2.4 \\
\hline & & & Low & 1.4 & 1 & 1.3 \\
\hline & \multirow{2}{*}{$\begin{array}{l}\text { Low } \\
\text { Nonuniform }\end{array}$} & & High & 1.8 & 1 & 2.0 \\
\hline & & & Low & 2.8 & 2 & 2.0 \\
\hline
\end{tabular}


Table 4. Random Effects Estimation of Permit Price

\begin{tabular}{cccc}
\hline Variable & \multicolumn{3}{c}{ Estimate } \\
\hline Intercept & 4.39 & $(0.52)$ & $* * *$ \\
HighMEP & 3.73 & $(0.65)$ & $* * *$ \\
Medium $\left(\pi_{H}\right) M E P$ & 2.41 & $(0.65)$ & $* * *$ \\
Medium $\left(\pi_{L}\right) M E P$ & 1.98 & $(0.65)$ & $* * *$ \\
LowStandard & 3.39 & $(0.83)$ & $* * *$ \\
LowStandard & 1.06 & $(0.13)$ & \\
$\times$ HighMEP & & & \\
LowStandard & -0.41 & $(0.13)$ & \\
$\times$ Medium $\left(\pi_{H}\right) M E P$ & & & \\
LowStandard & 2.57 & $(0.13)$ & $* *$ \\
$\times$ Medium $\left(\pi_{L}\right)$ MEP & 1.25 & $(0.46)$ & $* * *$ \\
\hline Noniform Allocation & & 157.33 & $* * *$ \\
\hline Wald $\chi^{2}(8)$ & &
\end{tabular}

4060 observations. Standard errors in parenthesis. ** $p<0.05$; *** $p<0.01$. 
Table 5. Random Effects Estimation of Individual Violations (Emissions Trading)

\begin{tabular}{|c|c|c|c|c|c|}
\hline \multirow{2}{*}{$\begin{array}{l}\text { Variable } \\
\text { Intercept }\end{array}$} & \multicolumn{2}{|l|}{ Model 1} & \multicolumn{3}{|c|}{ Model 2} \\
\hline & $2.47(0.27)$ & $* * *$ & 2.54 & $(0.76)$ & $* * *$ \\
\hline NetSeller & $-0.68(0.15)$ & $* * *$ & -1.19 & $(0.77)$ & \\
\hline HighMB & $0.03(0.14)$ & & 0.40 & $(0.77)$ & \\
\hline HighMEP & $-3.03(0.24)$ & $* * *$ & -3.56 & $(0.57)$ & $* * *$ \\
\hline $\operatorname{Medium}\left(\pi_{H}\right) M E P$ & $-1.50(0.21)$ & $* * *$ & -1.70 & $(0.44)$ & $* * *$ \\
\hline $\operatorname{Medium}\left(\pi_{L}\right) M E P$ & $-1.79(0.22)$ & $* * *$ & -1.98 & $(0.42)$ & $* * *$ \\
\hline PriceHat & $0.10(0.03)$ & $* * *$ & 0.12 & $(0.12)$ & \\
\hline PriceHat $\times$ NetSeller & & & 0.00 & $(0.12)$ & \\
\hline PriceHat $\times$ HighMB & & & -0.05 & $(0.12)$ & \\
\hline$H i g h M B \times H i g h M E P$ & & & 0.06 & $(0.59)$ & \\
\hline $\operatorname{HighMB} \times \operatorname{Medium}\left(\pi_{H}\right) M E P$ & & & 0.00 & $(0.46)$ & \\
\hline $\operatorname{HighMB} \times \operatorname{Medium}\left(\pi_{L}\right) M E P$ & & & -0.04 & $(0.45)$ & \\
\hline NetSeller $\times$ HighMEP & & & 1.01 & $(0.59)$ & $*$ \\
\hline NetSeller $\times$ Medium $\left(\pi_{H}\right) M E P$ & & & 0.41 & $(0.46)$ & \\
\hline NetSeller $\times$ Medium $\left(\pi_{L}\right) M E P$ & & & 0.44 & $(0.45)$ & \\
\hline Wald $\chi^{2}$ & 216.49 & $* * *$ & & 225.26 & $* * *$ \\
\hline
\end{tabular}

3168 observations. Standard errors in parenthesis. ${ }^{*} p<0.10 ; * * * p<0.01$ 
Table 6 - Marginal Productivity of Enforcement by Firm Type (Emissions Trading)

\begin{tabular}{|c|c|c|c|c|}
\hline & Enforcement Change & HighMB & LowMB & $\begin{array}{c}\text { Test of Equality } \\
\text { (p-value) }\end{array}$ \\
\hline \multirow{5}{*}{ 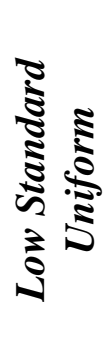 } & $\operatorname{Low}$ to Medium $\left(\pi_{L}\right)$ & -1.68 & -0.97 & 0.74 \\
\hline & Low to Medium $\left(\pi_{H}\right)$ & -1.55 & -1.04 & 0.59 \\
\hline & Low to High & -3.13 & -1.95 & 0.38 \\
\hline & $\operatorname{Medium}\left(\pi_{L}\right)$ to $H i g h$ & -1.45 & -0.97 & 0.31 \\
\hline & $\operatorname{Medium}\left(\pi_{H}\right)$ to High & -1.58 & -0.91 & 0.16 \\
\hline \multirow{5}{*}{ 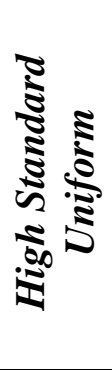 } & Low to Medium $\left(\pi_{L}\right)$ & -1.81 & -1.20 & 0.61 \\
\hline & Low to Medium $\left(\pi_{H}\right)$ & -1.46 & -0.89 & 0.68 \\
\hline & Low to High & -3.19 & -2.05 & 0.33 \\
\hline & $\operatorname{Medium}\left(\pi_{L}\right)$ to High & -1.38 & -0.85 & 0.27 \\
\hline & $\operatorname{Medium}\left(\pi_{H}\right)$ to High & -1.73 & -1.16 & 0.23 \\
\hline \multirow{5}{*}{ 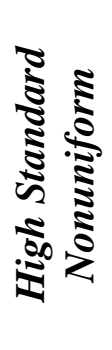 } & Low to Medium $\left(\pi_{L}\right)$ & -1.50 & -1.84 & 0.61 \\
\hline & Low to Medium $\left(\pi_{H}\right)$ & -1.16 & -1.49 & 0.64 \\
\hline & Low to High & -2.21 & -3.13 & 0.60 \\
\hline & $\operatorname{Medium}\left(\pi_{L}\right)$ to High & -0.72 & -1.29 & 0.39 \\
\hline & $\operatorname{Medium}\left(\pi_{H}\right)$ to High & -1.05 & -1.64 & 0.39 \\
\hline
\end{tabular}


Table 7. Summary Statistics for Individual Violations (Fixed Standards)

\begin{tabular}{|c|c|c|c|c|c|c|}
\hline & $\begin{array}{c}\text { Marginal } \\
\text { Expected Penalty }\end{array}$ & $\begin{array}{l}\text { Competitive } \\
\text { Equilibrium } \\
\end{array}$ & Firm MB & Mean & Median & $\begin{array}{l}\text { Standard } \\
\text { Deviation } \\
\end{array}$ \\
\hline \multirow{8}{*}{ 总营 } & \multirow{2}{*}{ High } & 1 & High & 0.6 & 1 & 1.0 \\
\hline & & 0 & Low & 0.1 & 0 & 0.3 \\
\hline & \multirow{2}{*}{$\operatorname{Medium}\left(\pi_{H}\right)$} & 5 & High & 4.1 & 4 & 2.1 \\
\hline & & 1 & Low & 1.2 & 1 & 0.6 \\
\hline & \multirow{2}{*}{$\operatorname{Medium}\left(\pi_{L}\right)$} & 5 & High & 3.0 & 2 & 3.6 \\
\hline & & 1 & Low & 1.4 & 1 & 1.5 \\
\hline & \multirow{2}{*}{ Low } & 7 & High & 5.0 & 4 & 2.2 \\
\hline & & 3 & Low & 2.1 & 2 & 0.8 \\
\hline \multirow{8}{*}{ 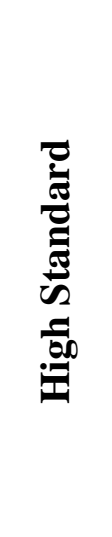 } & \multirow{2}{*}{ High } & 0 & High & 0.6 & 0 & 1.2 \\
\hline & & 0 & Low & 0.0 & 0 & 0.2 \\
\hline & \multirow{2}{*}{$\operatorname{Medium}\left(\pi_{H}\right)$} & 3 & High & 2.7 & 3 & 0.8 \\
\hline & & 0 & Low & 0.1 & 0 & 0.3 \\
\hline & \multirow{2}{*}{$\operatorname{Medium}\left(\pi_{L}\right)$} & 3 & High & 2.2 & 1.0 & 2.5 \\
\hline & & 0 & Low & 0.3 & 0 & 0.5 \\
\hline & \multirow{2}{*}{ Low } & 5 & High & 3.6 & 3 & 2.1 \\
\hline & & 1 & Low & 0.5 & 0 & 0.5 \\
\hline
\end{tabular}


Table 8. Random Effects Estimation of Individual Violations (Fixed Standards)

\begin{tabular}{|c|c|c|c|c|c|c|}
\hline \multirow{2}{*}{$\begin{array}{l}\text { Variable } \\
\text { Intercept }\end{array}$} & \multicolumn{3}{|c|}{ Model 1} & \multicolumn{3}{|c|}{ Model 2} \\
\hline & 2.25 & $(0.24)$ & $* * *$ & 1.99 & $(0.31)$ & $* * *$ \\
\hline $\operatorname{HighMB}$ & 2.00 & $(0.20)$ & $* * *$ & 3.06 & $(0.36)$ & $* * *$ \\
\hline HighMEP & -2.48 & $(0.28)$ & $* * *$ & -1.99 & $(0.48)$ & $* * *$ \\
\hline $\operatorname{Medium}\left(\pi_{H}\right) M E P$ & -0.77 & $(0.28)$ & $* * *$ & -0.80 & $(0.48)$ & * \\
\hline $\operatorname{Medium}\left(\pi_{L}\right) M E P$ & -1.06 & $(0.28)$ & $* * *$ & -0.61 & $(0.48)$ & \\
\hline HighStandard & -0.94 & $(0.20)$ & $* * *$ & -1.49 & $(0.36)$ & *** \\
\hline$H i g h M B \times H i g h M E P$ & & & & -2.56 & $(0.63)$ & *** \\
\hline $\operatorname{HighMB} \times \operatorname{Medium}\left(\pi_{H}\right) M E P$ & & & & -0.19 & $(0.63)$ & \\
\hline $\operatorname{HighMB} \times \operatorname{Medium}\left(\pi_{L}\right) M E P$ & & & & -1.44 & $(0.64)$ & ** \\
\hline HighStandard $\times$ HighMEP & & & & 1.45 & $(0.63)$ & ** \\
\hline HighStandard $\times$ Medium $\left(\pi_{H}\right) M E P$ & & & & 0.43 & $(0.63)$ & \\
\hline HighStandard $\times$ Medium $\left(\pi_{L}\right) M E P$ & & & & 0.40 & $(0.63)$ & \\
\hline HighStandard $\times$ HighMEP $\times$ HighMB & & & & -0.04 & $(0.63)$ & \\
\hline HighStandard $\times$ Medium $\left(\pi_{H}\right) M E P \times \operatorname{HighMB}$ & & & & -0.34 & $(0.72)$ & \\
\hline HighStandard $\times$ Medium $\left(\pi_{L}\right) M E P \times \operatorname{HighMB}$ & & & & -0.24 & $(0.72)$ & \\
\hline Wald $\chi^{2}$ & & 210.51 & $* * *$ & & 284.83 & $* * *$ \\
\hline
\end{tabular}


Table 9 - Marginal Productivity of Enforcement by Firm Type (Fixed Standards)

\begin{tabular}{|c|c|c|c|c|}
\hline & $\begin{array}{l}\text { Enforcement } \\
\text { Change }\end{array}$ & $\begin{array}{l}\text { HighMB } \\
\text { Firms }\end{array}$ & $\begin{array}{c}\text { LowMB } \\
\text { Firms }\end{array}$ & $\begin{array}{c}\text { Test of equality } \\
\text { (p-value) }\end{array}$ \\
\hline \multirow{5}{*}{ 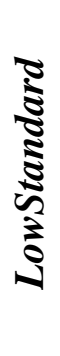 } & Low to Medium $\left(\pi_{L}\right)$ & -2.05 & -0.61 & 0.02 \\
\hline & $\operatorname{Low}$ to $\operatorname{Medium}\left(\pi_{H}\right)$ & -0.99 & -0.80 & 0.76 \\
\hline & Low to High & -4.48 & -1.92 & 0.00 \\
\hline & $\operatorname{Medium}\left(\pi_{L}\right)$ to High & -2.43 & -1.31 & 0.13 \\
\hline & $\operatorname{Medium}\left(\pi_{H}\right)$ to $H i g h$ & -3.49 & -1.12 & 0.00 \\
\hline \multirow{5}{*}{ 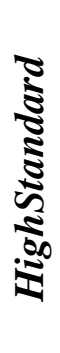 } & Low to Medium $\left(\pi_{L}\right)$ & -0.21 & -0.14 & 0.06 \\
\hline & Low to Medium $\left(\pi_{H}\right)$ & -0.91 & -0.37 & 0.39 \\
\hline & Low to High & -3.07 & -0.47 & 0.00 \\
\hline & $\operatorname{Medium}\left(\pi_{L}\right)$ to High & -1.65 & -0.26 & 0.06 \\
\hline & $\operatorname{Medium}\left(\pi_{H}\right)$ to $H i g h$ & -2.15 & -0.10 & 0.00 \\
\hline
\end{tabular}

